\title{
International collaboration to develop an interprofessional diabetic foot center at Black Lion Hospital, Ethiopia
}

\author{
Helen Y. Bitew*, Ahmed Reja, Abdurezak Ahmed, Brian Ostrow, RG Sibbald, Laura L. \\ Kozody, Julia Lowe
}

\section{Background}

- Type 2 Diabetes (DM2) is increasing everywhere with foot ulcers and amputations as a major cause of morbidity and disability.

-The International Diabetes Federation estimates there are 1.33 million people with DM2 in Ethiopia and 2.66 million with prediabetes. Studies in urban Ethiopia report a prevalence of 6-6.5\%.

-The Diabetes Center at Black Lion, the largest university hospital in Ethiopia, assesses 800 to 1000 patients with diabetes a week.

- There are no trained podiatrists or wound care specialists in Ethiopia.

- The Toronto Addis Ababa Academic Collaboration (TAAAC) was created in 2008 as a unique multi-professional educational initiative, partnering University of Toronto (UofT), Canada with Addis Ababa University (AAU)

\section{Aims}

To test if the Guyana South America model for a diabetic foot care program (I) would work in Addis Ababa

\section{Methods}

The steps are: assessing system barriers to implementation of best practices, training local key opinion leaders (KOLs) to work in an interprofessional team and establishing a center of excellence as a focus for local education and system change.

-Needs Assessment: An endocrinologist visiting Addis Ababa through TAAAC found conditions similar to those existing prior to the implementation of the Guyanese diabetic foot care program: health professionals working in silos, no comprehensive assessment process for people with diabetic foot ulcers, inappropriate use of antibiotics/dressings, patients presenting late for treatment, no systematic screening for high risk feet and suboptimal footwear. Foot ulcers with or without gangrene were the leading cause of admission to Black Lion Hospital, accounting for $39 \%$ of DM2 patients admitted in 20I0-20I3 (2). Patients admitted with diabetic foot problems have unacceptably high rates of amputation (47.2\%) and in-hospital mortality (2l\%) (3). An audit of people with diabetes assessed at the Diabetes Center calculated only $4.5 \%$ had had a foot exam in the last 5 years, $15.5 \%$ had previous ulcer, and $35.5 \%$ had at least one risk factor for ulceration.

- Key opinion leaders: Local leaders in Endocrinology and Orthopedic physicians within the Department of Medicine, College of Health Sciences and AAU were eager to improve diabetic foot care. Medical and nursing staff was willing to be trained as KOLs to spearhead change.

- Space was available to establish a center of excellence in the Diabetes Center and there was a well-established training program for rehabilitation specialists

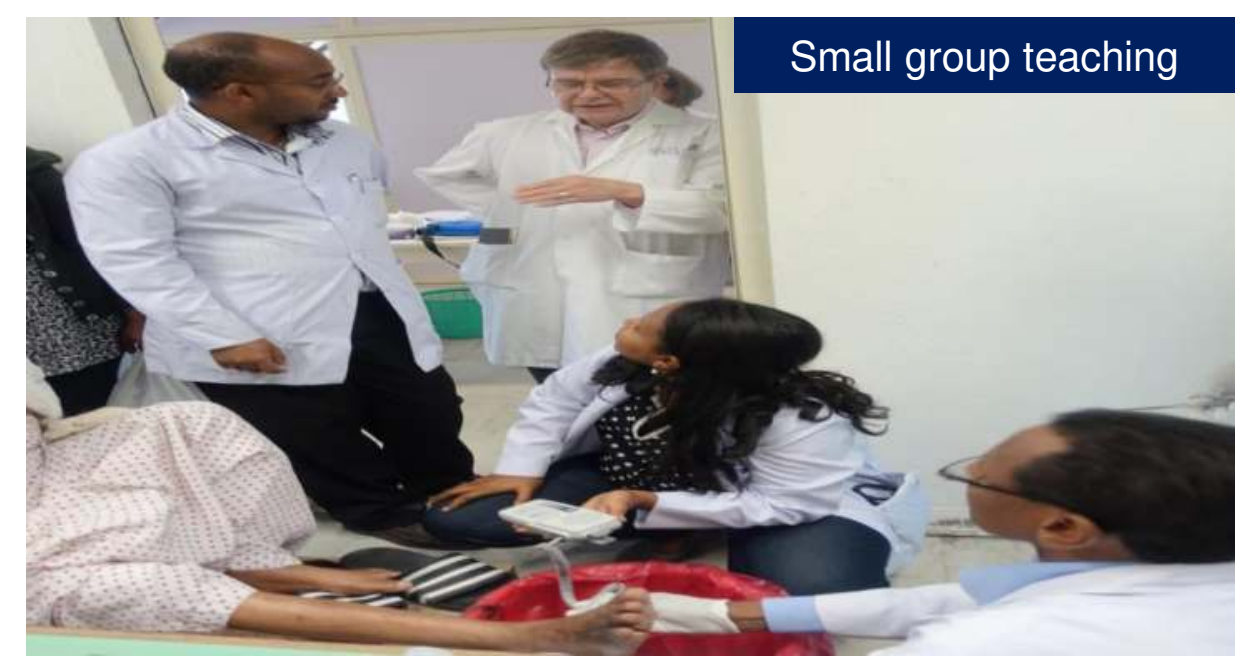

\section{References}

Lowe J, Sibbald RG, Taha NY, Lebovic G, Martin C, Bhoj I, et al. (2015) The Guyana Diabetes and Foot Care Project: A Complex Quality Improvement Intervention to Decrease Diabetes-Related Major Lower Extremity Amputations and Improve Diabetes Care in a Lower-Middle-Income Country. PLoS Med12(4): e1001814. https://doi.org/10.1371/journal.pmed.1001814

Gizaw, M., Harries, A. D., Ade, S., Tayler-Smith, K., Ali, E., Firdu, N., \& Yifter, H. (2015). Diabetes mellitus in Addis Ababa, Ethiopia: admissions, complications and outcomes in a large referral hospital. Public Health Action, 5(1), 74-78

Wondwossen A, Reja A, Amare A. (2011) Diabetic foot disease in Ethiopian patients: A hospital based study. Ethiop J Health Dev, 25(1):17-21

\section{Results}

Prevention: Screening was started in the diabetes clinic using the validated Simplified 60 second tool.

Interprofessional education initiatives and KOL team: Two endocrinologists and one nurse have been trained in wound care through the International Interprofessional Wound Care Course (IIWCC). Another endocrinology fellow and nurse started this year. In October 2016, a team from UofT consisting of an endocrinologist, wound care specialist and chiropodist visited the clinic for a week of teaching and practical training. During this week, there were 4 education sessions and 2 foot clinics attended by close to 120 attendees: orthopedic staff and residents, medical residents, nurses and orthopedic nurses Infrastructure: Three rooms in the Diabetes Center were renovated to function as a foot care clinic through funding from the Banting and Best Diabetes Centre (UofT), which also donated plantar pressure redistribution devices/ supplies and OR equipment.

System Change: Access to rehabilitation services on site remains a challenge.
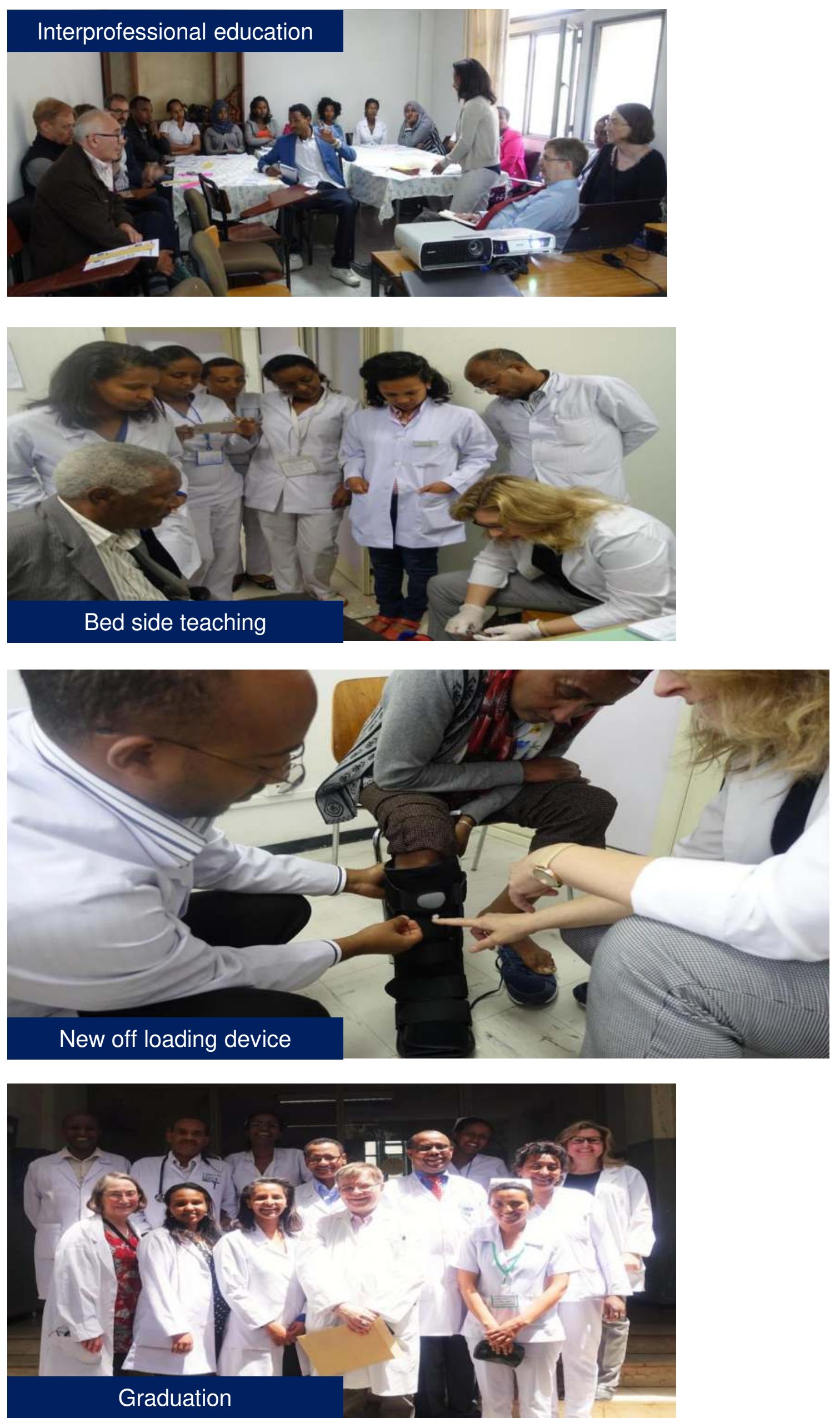

\section{Discussion}

Early changes have been made and enthusiasm is high. Future plans include further visits by Canadian and US foot care experts for hands-on training, and visits by KOLs to overseas centers of excellence to improve practical skills. We would also like to establish centers of excellence outside the capital by funding and training health care profession 